\title{
Eruptive tufted angiomas in a patient with Crohn's disease
}

\section{A M Al-Za'abi, D Ghazarian, G R Greenberg, J C Shaw}

J Clin Pathol 2005;58:214-216. doi: 10.1136/jcp.2004.019018

Angioblastoma is a rare, benign vascular tumour composed of undifferentiated mesenchymal cells with a tendency to form lumina. This entity was first described by Nakagawa in 1949 as angioblastoma, and Wilson Jones was the first to use the term "tufted angioma" in 1976. Tufted angiomas usually occur in infancy and spread slowly. This report describes lesions from the right side of the forehead, forearms, and thighs of a 24 year old man with a four year history of Crohn's disease, who was receiving infliximab in addition to long standing azathioprine and ciprofloxacillin. He developed numerous small itchy erythematous vascular appearing papules, which on histological examination resembled tuffed angiomas, showing the classic "cannon ball" appearance. The lesions regressed within three months. This case may represent an eruptive acquired tuffed angioma in which immunosuppression or drug induced modification of angiogenesis played a role in its development and regression. One previous case of eruptive tufted angioma has been reported in an immunosuppressed patient.

A 24 year old, human immunodeficiency virus negative man with a four year history of Crohn's disease developed pruritic lesions on the right side of the forehead, thighs, and forearms. He was receiving intravenous infliximab every eight weeks, in addition to his long standing treatment of azathioprine (100 mg/day) and ciprofloxacillin (1500 mg/day). The papules developed two months after starting infliximab. Physical examination revealed several erythematous, vascular appearing papules approximately $0.5 \mathrm{~cm}$ in diameter (fig 1). The differential diagnosis included prurigo papules and he was started on fluocinonide $0.05 \%$ ointment and a punch biopsy was done. Another punch biopsy was taken three weeks after the first one. There was no change in his treatment for Crohn's disease. The lesions involuted over three months.

\section{PATHOLOGICAL FINDINGS}

The first specimen showed focally ulcerated skin with several small round to elongated compact cellular lobules of vascular proliferation in the papillary and reticular dermis (fig 2). This represents the characteristic "cannon ball" appearance of tufted angioma. At high power, these "tufts", which were varied in size and randomly dispersed, have semilunar clefts and slit-like spaces composed of tightly packed monomorphous endothelial and perithelial cells (fig 3). These represent uncanalised cellular aggregates or newly formed vessels with a varying degree of canalisation. No giant cells, cellular atypia, or pleomorphism were noted. Immunohistochemical studies were performed and the tumour cells stained positive for factor VIII, CD34, CD 31 (fig 4), smooth muscle actin, muscle specific antigen, and vimentin. The lesions were negative for keratins and factor XIIIa.

The second biopsy showed acanthosis with parakeratosis, focal ulceration, and superficial dermal fibrosis. At one side of the ulcerated area and within the dermis, proliferations of endothelial cells are seen (fig 5). The features of the second biopsy were consistent with a tufted angioma in regression.

\section{DISCUSSION}

Solitary tufted angioma, also called angioblastoma, is a rare benign vascular tumour first described by Nakagawa in 1949. ${ }^{1}$ It has been suggested that this tumour is composed of undifferentiated atypical mesenchymal cells. In 1976, Wilson Jones $^{2}$ described it again but called it tufted angioma. This new term was introduced to avoid confusion with cerebellar haemangioblastoma. In 1989, Wilson Jones and Orkin separated it from all the variants of lobular capillary haemangioma. ${ }^{3}$ More than 200 cases have been reported, mainly in the Japanese literature, ${ }^{4}$ and malignant transformation has never been described.

Solitary tufted angioma is a rare, recurring, slowly growing vascular tumour with a variable clinical morphology that can present as red to purple and more rarely bluish papules or plaques. The lesions range from 2 to $5 \mathrm{~cm}$ in size but may be larger. ${ }^{5}$ Hypertrichosis can also be seen in association with tufted angioma. ${ }^{56}$ The lesions may persist for years and can regress spontaneously. Localised hyperhidrosis was present in some of the cases. ${ }^{7}$ Most of the lesions are asymptomatic but may present with tenderness or even pain. Tenderness, hypertrichosis, and induration can be useful in differentiating tufted angioma from common haemangioma. ${ }^{5}$ The lesions can be found anywhere, but are mainly seen on the neck, trunk, and occasionally on the extremities. Although this condition is entirely benign, extensive involvement is

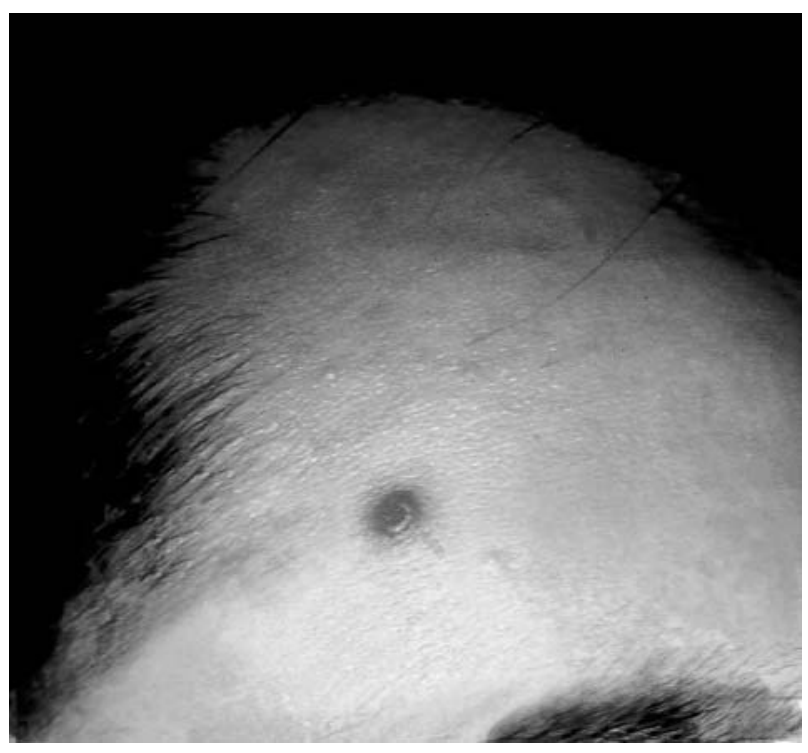

Figure 1 Tufted angioma, forehead lesion. This photograph is reproduced with the full consent of the patient. 


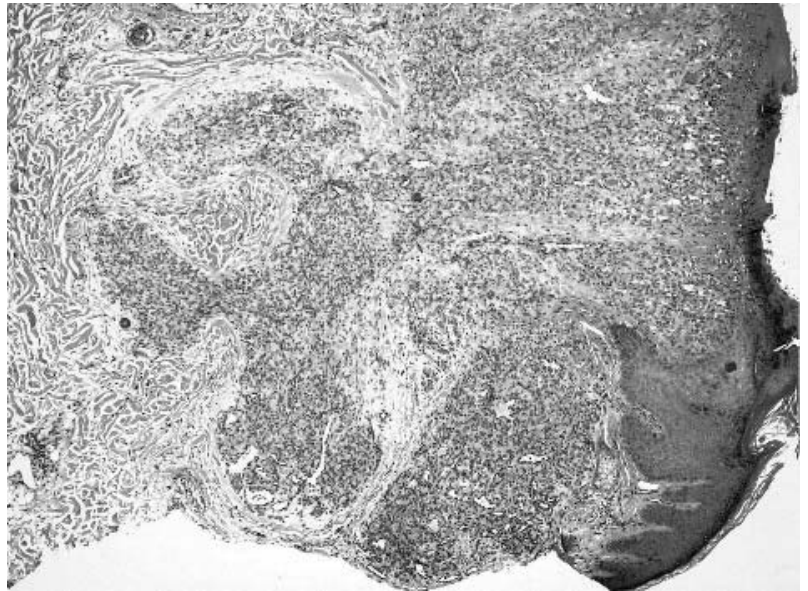

Figure 2 Tufted angioma, characterised by focally ulcerated skin with several small round to elongated compact cellular lobules of vascular proliferation in the papillary and reticular dermis; haematoxylin and eosin stain; original magnification, $\times 5$.

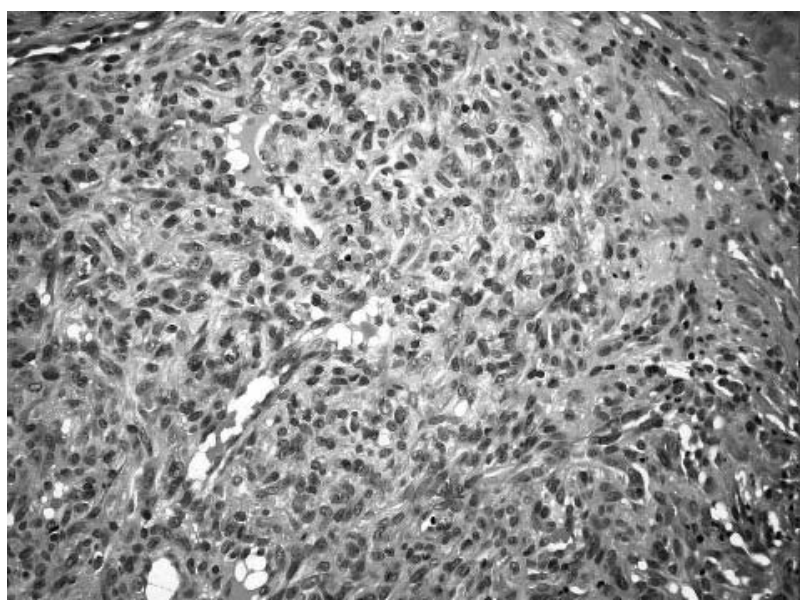

Figure 3 Tufted angioma: the tufts were varied in size and randomly dispersed. They had semilunar clefts and slit-like spaces composed of tightly packed monomorphous endothelial and perithelial cells;

haematoxylin and eosin stain; original magnification, $\times 25$.

common and this can result in a disfiguring clinical appearance.

Most patients with tufted angioma are under 10 years of age and more than $50 \%$ of cases occur during the lst year of life. There is no sex predominance. Most have an insidious onset and gradually increase in size. Spontaneous involution has been reported, particularly in infancy, after delivery, and after liver transplantation. ${ }^{8}{ }^{9}$ Central regression has also been reported. ${ }^{4}$

"Kaposi's sarcoma and bacillary angiomatosis are the two most commonly encountered vascular proliferations seen in immunocompromised patients and have to be ruled out"

The histological characteristics of tufted angiomas are small, numerous, circumscribed angiomatous tufts and lobules of vascular proliferation randomly scattered along the superficial and the deep vascular plexus in the dermis. Tufts are concentrically whorled and composed of endothelial cells with small hyperchromatic round to ovoid nuclei,

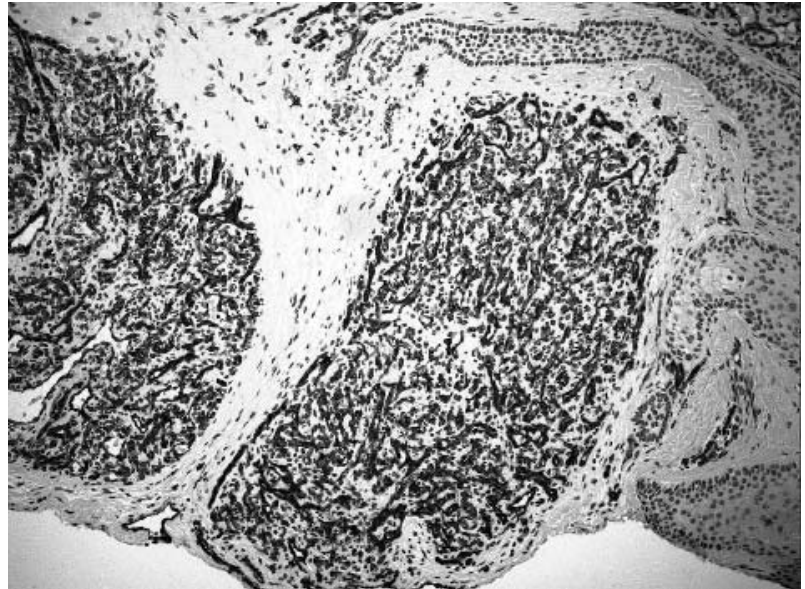

Figure 4 Original lesion showing immunohistochemical positivity for CD31; original magnification, $\times 10$.

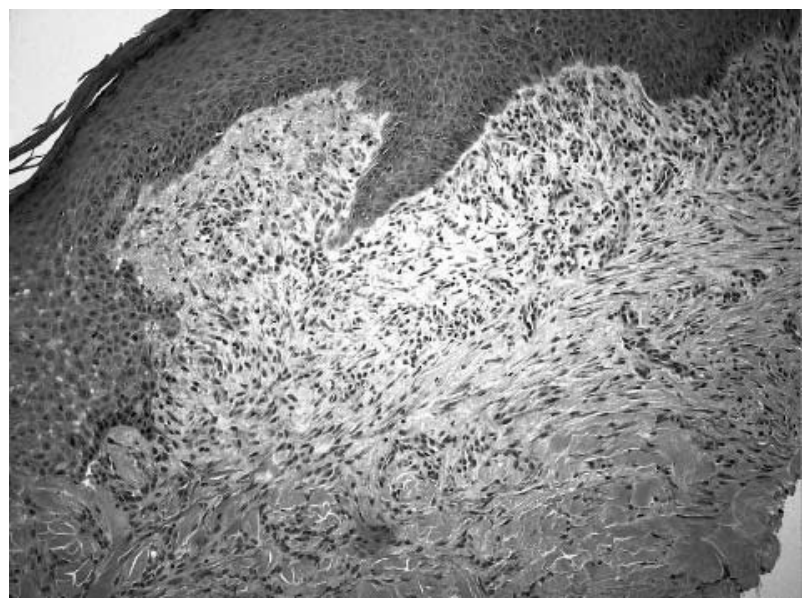

Figure 5 Second biopsy showing features of a regressing lesion; haematoxylin and eosin stain; original magnification, $\times 10$.

surrounded by pericytes. Some of the tufts are present in the vicinity of the eccrine glands and proliferation of eccrine glands has been described in a few cases. ${ }^{10}{ }^{11}$

At the periphery of the lobules, semilunar slit-like or crescent shaped spaces are found. Dilated lymphatic capillaries have also been described. The lesions do not extend beneath the deep fascia, ${ }^{3}{ }^{12}$ except in one case where the lesion extended to the superficial muscle fibres. ${ }^{13}$ A slight increase of mucinous material in the vicinity of the angiomatous foci has been seen in some cases. Inflammatory cells are normally absent or insignificant. Clinically uninvolved skin around the lesion may be involved histologically, making surgical resection difficult, and increasing the chance of recurrence.

The differential diagnosis includes juvenile capillary (strawberry) angioma; eccrine haemangiomatous hamartoma when the vascular element is accompanied by hyperplasia of eccrine sweat glands ${ }^{14}$; lobular capillary haemangioma; bacillary angiomatosis; and spindle cell haemangioendothelioma, ${ }^{12}{ }^{15}$ which was described by Weiss and Enzinger in 1986, when there are nodules of uncanalised vascular lesions and the cannon ball distribution is not present. Kaposi's sarcoma and angiosarcoma should be excluded when both vascular proliferation is infiltrative and exhibits some degree of cytological atypia, multilayering of 


\section{Take home messages}

- We describe a case of angioblastoma, a rare, benign vascular tumour, also known as "tufted angioma", in a 24 year old man with a four year history of a Crohn's disease, who was receiving infliximab in addition to long standing azathioprine and ciprofloxacillin

- He developed numerous small itchy erythematous vascular appearing papules, which on histological examination resembled tufted angiomas, but regressed within three months

- This case may represent an eruptive acquired tufted angioma in which immunosuppression or drug induced modification of angiogenesis played a role in its development and regression

- This is the second case of eruptive tufted angioma to be reported in an immunosuppressed patient

endothelial cells, and abnormal mitotic figures. ${ }^{37}$ Kaposi's sarcoma and bacillary angiomatosis are the two most commonly encountered vascular proliferations seen in immunocompromised patients and have to be ruled out.

Immunohistochemical staining of vascular antigens is helpful. Endothelial cells are positive for factor VIII and pericytes are positive for muscle specific antigen and smooth muscle actin. Non-immunological staining using Ulex europaeus agglutinin I (UEA-I) can also be useful because cells positive for this antigen can be found around the vascular lumina within the tufts. Most of the tumour cells will stain positive for CD34. Factor VIII related antigen expression is weak or absent. ${ }^{16}$

Surgical excision or cryosurgery is the most successful treatment for this condition, but may fail because of the involvement of clinically normal skin. Other methods used with variable results include pulse dye laser, interferon $\alpha$, corticosteroids, and radiotherapy. ${ }^{311}$

One previous case of eruptive vascular lesions resembling tufted angiomas has been reported in a patient after liver transplantation. ${ }^{17}$ In that case, the lesions were clinically and histologically similar to those seen in our case, the patient was receiving azathioprine, was immunocompromised, and all the lesions involuted spontaneously. The lesions in that patient were limited to the right axilla and arm.

Infliximab, anti-tumour necrosis factor $\alpha$ antibody, is known to have antiangiogenic effects. In one study, infliximab resulted in a considerable improvement in synovitis by causing a reduction in synovial angiogenesis. The effect was thought to be related to the modulation of several molecular factors involved in angiogenesis, such as vascular endothelial growth factor (VEGF) and its receptors VEGFR-1 and VEGFR-2, the angiogenic chemokine SDF-1, and Tie 2 receptor. ${ }^{18}$ The wide distribution in our case suggests a systemic angiogenic process. Whether this was secondary to azathioprine immunosuppression or to Crohn's disease remains unclear. Infliximab might have contributed to the regression of the lesions.

\section{Authors' affiliations}

A M Al-Za'abi, D Ghazarian, Department of Pathology, University of Toronto, Toronto M5T 2S8, Canada

G R Greenberg, J C Shaw, Department of Medicine, University of Toronto

The photograph is reproduced with the full consent of the patient.

Correspondence to: Dr J C Shaw, Division of Dermatology, Western Toronto Hospital, 399 Bathurst Street, EW 8-517 Toronto M5T 2S8,

Canada; jc.shaw@utoronto.ca

Accepted for publication 2 July 2004

\section{REFERENCES}

1 Nakagawa K. Case report of angioblastoma of the skin [in Japanese]. Jpn J Dermatol 1949:59:92-4.

2 Wilson Jones E. Malignant vascular tumours. Clin Exp Dermatol 1976;1:287-312.

3 Wilson Jones E, Orkin M. Tufted angioma (angioblastoma): a benign progressive angioma, not to be confused with Kaposi's sarcoma or low grade angiosarcoma. J Am Acad Dermatol 1989;20:214-25.

4 Ban M, Kamiya H, Kitajima Y. Tufted angioma of adult onset, revealing abundant eccrine glands and central regression. Dermatology 2000;201:68-70.

5 Wong SN, Tay YK. Tufted angioma: a report of five cases. Pediatr Dermatol 2002; 19:388-93.

6 Herron MD, Coffin CM, Vanderhooft SL. Tufted angiomas: variability of the clinical morphology. Pediatr Dermatol 2002;19:394-401.

7 Chu KH, Kim SH, Park KC, et al. Angioblastoma (Nakagawa)-is it the same as tufted angioma? Clin Exp Dermatol 1991;16:110.

8 Lam WY, Lai FMM, Look CN, et al. Tufted angioma with complete regression. J Cutan Pathol 1994;21:461-6.

9 Kano Y, Nakajo T, Nagashima M. Angioblastoma cases showing spontaneous regression [in Japanese]. Hifuka No Rinsho 1982;24:1123-7.

10 Murakami M, Nitta Y, Ikeya T, et al. Two cases of angioblastoma (Nakagawa): a one month baby and an 84-year old man [in Japanese] Hifuka No Rinsho 1997;39:925-9.

11 Park KC, Ahn PS, Lee YS, et al. Treatment of angioblastoma with recombinant interferon- $\alpha 2$. Pediatr Dermatol 1995;12:184-6.

12 Allen PW, Ramakrishna B, MacCormac LB. The histiocytoid hemangiomas and other controversies. Pathol Annu 1992;2:51.

13 Munn SE, Jackson JE, Russell Jones R. Tufted haemangioma responding to high-dose systemic steroids: a case report and review of the literature. Clin Exp Dermatol 1994;19:511-14.

14 Hyman $A B$, Harris $H$, Brownstein $M H$. Eccrine angiomatous hamartoma. N Y State J Med 1968;68:2803-6.

15 Weiss SW, Enzinger FM. Spindle cell hemangioendothelioma and Kaposi's sarcoma. Am J Surg Pathol 1986;10:521.

16 Okada E, Tamura A, Ishikawa $\mathrm{O}$, et al. Tufted angioma (angioblastoma): case report and review of 41 cases in the Japanese literature. Clin Exp Dermatol 2000;25:627-30.

17 Chu $P$, LeBoit PE. An eruptive vascular proliferation resembling acquired tuffed angioma in the recipient of a liver transplant. J Am Acad Dermatol 1992;26:322-5.

18 Canete JD, Pablos JL, Sanmarti R, et al. Antiangiogenic effects of anti-tumor necrosis factor alpha therapy with infliximab in psoriatic arthritis. Arthritis Rheum 2004;50:1636-41. 